\title{
Assessing Sleep Disturbance in Ecstasy Users: A Questionnaire Study
}

\author{
R.P. Ogeil ${ }^{*}$, S.M.W. Rajaratnam and J.H. Broadbear \\ School of Psychology and Psychiatry, Monash University, Clayton, VIC 3800, Australia
}

Keywords: Ecstasy, sleep disturbance, polydrug use.

\section{INTRODUCTION}

Ecstasy users have previously reported subjective problems with sleep following use [1,2], and laboratory studies have demonstrated altered sleep architecture in ecstasy users [3]. The current study examined whether ecstasy contributed to sleep disturbance to a clinically significant level in users in the presence or absence of polydrug use, and determined the extent to which the amount or frequency of reported ecstasy use was associated with sleep complaints.

\section{RESULTS}

A significant proportion of participants who took ecstasy had PSQI scores above the threshold used to identify people with clinically significant sleep disturbance $(n=173,69.5 \%)$, while a smaller number reported problems with excessive daytime sleepiness $(n=41,15.1 \%)$. Frequency of ecstasy use did not affect the degree of reported sleep disturbance; however participants who took larger amounts of ecstasy on occasions when they used it reported poorer sleep quality. After controlling for polydrug use, for all drug-using groups
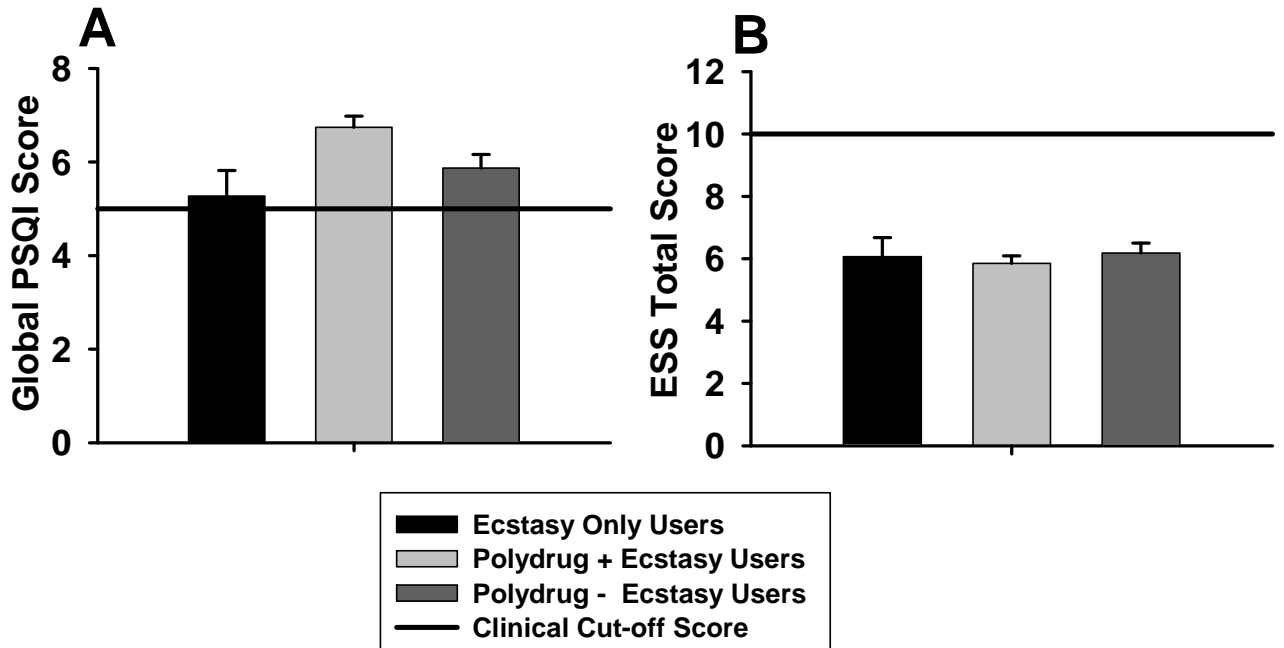

Fig. (1). Group mean +SEM scores on the PSQI (Panel A) and ESS (Panel B) sleep instruments, with clinical cut-off scores indicated with a horizontal line.

\section{METHODS}

Self-reports of questionnaire participants were used to classify them as ecstasy only users $(n=34)$, polydrug ecstasy users $(n=236)$ or polydrug users who did not take ecstasy $(n=125)$. Participants completed a measure of sleep quality (the Pittsburgh Sleep Quality Index (PSQI)), a measure of excessive daytime sleepiness (the Epworth Sleepiness Scale (ESS)) and a series of questions related to ecstasy and other drug use. Participants' data were collected on-line via a questionnaire hosted by Survey Methods ${ }^{\circledR}$.

*Address correspondence to this author at the School of Psychology and Psychiatry, Monash University, Clayton, VIC 3800, Australia; Tel: +613 99059449; Fax:+613 99053948; E-mail: Rowan.Ogeil@monash.edu remained above the threshold for clinically significant sleep disturbance (see Fig. 1); however, levels of excessive daytime sleepiness as measured by the ESS were similar to levels reported in the general population (10.9\%) [4].

\section{DISCUSSION}

The present study found that sleep complaints were common in ecstasy users, substantiating the premise that sleep may be a useful neurobehavioural marker for detection of functional deficits post-ecstasy use [5]. Previously, sleep disturbances have been noted in current [6] and abstinent [7] ecstasy users, and the current study extended these findings by demonstrating that the amount of ecstasy used was an important contributer to self-reported sleep problems. While polydrug use is common amongst ecstasy users [8] making it difficult to assess the contribution of ecstasy to adverse 
events following use [9], the current study addressed this by separating participants according to whether they were ecstasy-only users, polydrug ecstasy users, or polydrug users who did not use ecstasy. While the polydrug ecstasy users had the highest reported level of sleep disturbance, the potential contribution of ecstasy was highlighted by the observation that the ecstasy-only group also had a mean PSQI score $>5$, suggesting that ecstasy contributes to clinically significant sleep disturbance.

\section{CONCLUSIONS}

A significant proportion of ecstasy users have problems with sleep quality but not with excessive daytime sleepiness. This perceived reduction in sleep quality may contribute to negative effects on mood and cognition [10] which have been reported following ecstasy use.

\section{REFERENCES}

[1] McCann U, Ricaurte G. Effects of (+-) 3, 4methylenedioxymetamphetamine (MDMA) on sleep and circadian rhythms. Scientific World J 2007; 7: 231-8.

[2] Carhart-Harris RL, Nutt DJ, Munafo M, Wilson SJ. Current and former ecstasy users report different sleep to matched controls: a web-based questionnaire study. J Psychopharmacol 2009; 23: 24957.

[3] Allen RP, McCann UD, Ricaurte GA. Persistent effects of (+-) 3, 4-methylenedioxymethamphetamine (MDMA, "Ecstasy") on human sleep. Sleep 1993; 16: 560-4.

[4] Johns M, Hocking B. Daytime sleepiness and sleep habits of Australian workers. Sleep 1997; 20: 844-9.

[5] McCann UD, Peterson SC, Ricaurte GA. The effect of catecholamine depletion by Alpha-Methyl-Para-Tyrosine on measures of cognitive performance and sleep in abstinent MDMA users. Neuropsychopharmacology 2007; 32: 1695-706.

[6] Topp L, Hando J, Dillon P, Roche A, Solowij N. Ecstasy use in Australia: patterns of use and associated harm. Drug Alcohol Depend 1999; 55: 105-15.

[7] McCann UD, Wilson MJ, Sgambati FP, Ricaurte GA. Sleep deprivation differentially impairs cognitive performance in abstinent methylenedioxymethamphetamine ("Ecstasy") users. J Neurosci 2009; 29: 14050-6.

[8] Parrott AC, Milani RM, Gouzoulis-Mayfrank E, Daumann J. Cannabis and Ecstasy/MDMA (3,4-methylenedioxymethamphetamine): an analysis of their neuropsychological interactions in recreational users. J Neural Transm 2007; 114: 959-68.

[9] Gouzoulis-Mayfrank E, Daumann J. The confounding problem of polydrug use in recreational ecstasy/MDMA users: a brief overview. Psychopharmacology 2006; 20: 188-93.

[10] Pirona A, Morgan MJ. An investigation of the subacute effects of ecstasy on neuropsychological performance, sleep and mood in regular ecstasy users. J Psychopharmacol 2010; 24: 175-85.

(C) Ogeil et al.; Licensee Bentham Open.

This is an open access article licensed under the terms of the Creative Commons Attribution Non-Commercial License (http://creativecommons.org/licenses/ by-nc/3.0/) which permits unrestricted, non-commercial use, distribution and reproduction in any medium, provided the work is properly cited. 